\title{
Roles of FGF19 in Liver Metabolism
}

\author{
S. KIR ${ }^{1}$, S.A. KLIEWER ${ }^{1,2}$, AND D.J. MANGELSDORF ${ }^{1,3}$ \\ ${ }^{1}$ Department of Pharmacology, University of Texas Southwestern Medical Center, Dallas, Texas 75390 \\ ${ }^{2}$ Department of Molecular Biology, University of Texas Southwestern Medical Center, \\ Dallas, Texas 75390 \\ ${ }^{3}$ Howard Hughes Medical Institute, University of Texas Southwestern Medical Center, \\ Dallas, Texas 75390 \\ Correspondence: davo.mango@utsouthwestern.edu
}

\begin{abstract}
Fibroblast growth factor 19 (FGF19) is an ileum-derived postprandial enterokine that governs bile acid and nutrient metabolism. Synthesis of FGF19 is up-regulated by bile acids and, conversely, bile acid synthesis is down-regulated by FGF19. FGF19 also controls gallbladder volume. FGF19 has been shown to have profound effects on glucose and lipid metabolism. Recent studies have described FGF19 as a postprandial regulator of hepatic glucose and protein metabolism. Like insulin, FGF19 induces protein and glycogen synthesis and suppresses gluconeogenesis in liver. However, unlike insulin, FGF19 does not stimulate lipogenesis. A key difference between FGF19 and insulin lies in their use of different cellular signaling pathways. The beneficial effects of FGF19 on liver metabolism raise the question of whether FGF19 and its variants can be used as therapeutic agents in the treatment of diabetes.
\end{abstract}

Fibroblast growth factor 19 (FGF19) is a member of a subfamily of FGFs that includes FGF21 and FGF23; each member of this subfamily functions as an important regulator of nutrient metabolism. Unlike other FGFs that have paracrine and autocrine functions, FGF19 subfamily members have reduced affinity for heparin, which permits them to escape the extracellular matrix and circulate as endocrine hormones. Although FGF21 and FGF23 have been shown to regulate lipid and phosphate metabolism, respectively, FGF19 (also called FGF15 in rodents) has been characterized as an ileum-derived enterokine that governs bile acid metabolism (Beenken and Mohammadi 2009). Here, FGF19 and its recently reported roles in hepatic glucose and protein metabolism, as well as its regulation of bile acid synthesis, will be discussed.

The primary source of endocrine FGF19 is the ileum, where FGF19 expression is controlled by the bile acid nuclear receptor FXR (Holt et al. 2003; Inagaki et al. 2005). Bile acids released into the intestine after a meal bind to and activate FXR and thereby induce expression of FGF19. In humans, the postprandial rise in serum bile acids is followed by a synchronous serum FGF19 peak that takes place $\sim 3 \mathrm{~h}$ after a meal (Lundasen et al. 2006). This close relationship between FGF19 and bile acids renders FGF19 a postprandial hormone.

On its own, FGF19 fails to activate FGF receptors (FGFRs). This is believed to be caused by FGF19's reduced affinity toward extracellular matrix glucosaminoglycans that promote the interaction between other FGFs and their receptors. Recent studies have shown that FGF19 requires the presence of another transmembrane protein, $\beta$-Klotho. $\beta$-Klotho enables FGF19 binding to FGFR4 (its preferred receptor) and acts as the obligatory coreceptor that permits FGF19-FGFR4 signaling (Kurosu et al. 2007; Lin et al. 2007). Thus, to be a target of FGF19, a tissue must express both FGFR4 and $\beta$-Klotho. This requirement makes liver the main target of endocrine FGF19 as both FGFR4 and $\beta$-Klotho are highly expressed in this organ.

\section{FGF19 REGULATES BILE ACID HOMEOSTASIS}

Bile acids are strong detergents produced by catabolism of cholesterol in liver. After a meal, bile acids stored in the gallbladder are released into the intestine to facilitate solubilization and absorption of lipids and lipidsoluble vitamins. Because of their toxic nature, the synthesis of bile acids must be tightly regulated. This regulation takes place at the level of gene expression through a bile acid-dependent negative feedback mechanism. Cholesterol $7 \alpha$-hydroxylase (CYP7A1) is the enzyme that catalyzes the first and the rate-limiting step in the major bile acid synthesis pathway, and it is the main target of the feedback regulation. Bile acids repress transcription of the CYP7A1 gene and thereby downregulate their own synthesis.

The nuclear receptor FXR has been shown to play a crucial role in regulation of bile acid homeostasis. The negative feedback regulation of bile acid synthesis is abolished in FXR-deficient mice and, thus, Cyp7al expression levels are elevated in these animals (Sinal et al. 2000). Initially, it was assumed that FXR function in liver was solely responsible for $C y p 7 a 1$ repression. However, studies have shown that the negative feedback 
regulation also requires FXR-dependent synthesis of FGF19 in the intestine. As first described by Holt et al. (2003), FGF19 is a direct bile acid-dependent target gene of FXR. The FGF19 promoter contains a single FXR-response element that is conserved in rodents and human. FGF19 alone is able to repress CYP7A1 mRNA levels in human primary hepatocytes (Holt et al. 2003). In vivo administration of bile acids or an FXR agonist (GW4064) in mice induces FGF15 expression in epithelial cells of the ileum and both FGF15 and FGF19 can completely suppress Cyp $7 a 1$ expression in liver (Inagaki et al. 2005). FGF15/19* fails to repress Cyp7al in $\mathrm{Fgfr} 4^{-/-}$mice, demonstrating the specificity of action of FGF15 (Fig. 1).

Further evidence for the requirement for FGF15/19 in maintaining proper bile acid homeostasis has come from analysis of various animal models harboring deletions on the FGF15 signaling axis. Fgfr4 ${ }^{-/-}, \mathrm{Klb}^{-/-}$(i.e., $\beta$-Klotho-null), and $F g f 15^{-/}$mice all have increased levels of Cyp7al expression as well as an elevated bile acid pool size ( $Y u$ et al. 2000; Inagaki et al. 2005; Ito et al. 2005). Moreover, administration of GW4064 or the endogenous FXR agonist, cholic acid, fails to repress Cyp7al in Fgfr4 ${ }^{-/-}$or $F g f 15^{-/-}$mice. In addition, GW4064 was shown to repress Cyp7al in liver-specific $\mathrm{Fxr}^{-1-}$ mice; however, this effect was completely abolished in ileum-specific $\mathrm{Fxr}^{-/-}$mice (Kim et al. 2007). These findings confirmed that FXR-mediated negative feedback regulation is dependent on enterohepatic signaling mediated by FGF15/19.

The importance of the role of FGF19 in maintaining proper bile acid homeostasis has been highlighted further by clinical studies. In humans, serum FGF19 levels peak after a postprandial rise in serum bile acid levels and this peak is followed by a declining phase of bile acid synthesis (Lundasen et al. 2006). In addition, patients with primary bile acid malabsoption syndrome have reduced FGF19 production by the ileum, which is associated with increased bile acid synthesis and bile acid diarrhea (Walters et al. 2009). Moreover, inflammatory bowel disease patients with resected distal ileum exhibit dysregulated bile acid metabolism with reduced serum FGF19 and elevated serum bile acid levels (Lenicek et al. 2011).

Although there has been considerable progress in the field of bile acid regulation, the exact mechanism of Cyp7al repression remains elusive. In addition to FGF15/19 signaling pathway, it has been shown that orphan nuclear receptor small heterodimer partner (SHP) is required for repression of Cyp 7al, because administration of bile acids or FGF15/19 fails to repress Cyp 7 al transcription in SHP-deficient mice (Inagaki et al. 2005). However, the mechanism by which the FGF15/ 19-FGFR4- $\beta$-Klotho signaling pathway intersects with the SHP repression pathway to mediate repression of Cyp 7 al transcription remains the focus of current research.

\footnotetext{
${ }^{*}$ In this review, the term FGF15/19 is used when referring to experiments performed with both the mouse (FGF15) and the human (FGF19) orthologs of the hormone.
}

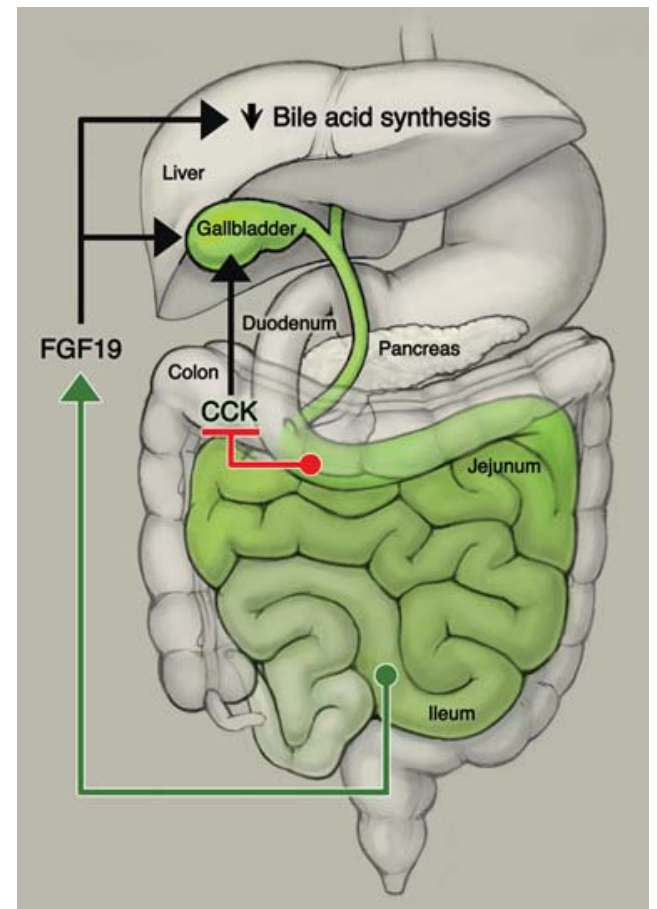

Figure 1. Fibroblast growth factor 19 (FGF19) is an ileumderived postprandial enterokine that regulates hepatic bile acid metabolism. Bile acids that are postprandially released into the intestine suppress cholecystokinin (CCK) production in the duodenum and, thus, block further gallbladder contraction. In the distal ileum, bile acids induce production of FGF19, which induces gallbladder relaxation and filling and suppresses hepatic bile acid synthesis.

A second role for FGF15/19 in bile acid regulation has been described in the gallbladder. $\mathrm{Fgfl5^{-/- }}, \mathrm{Fg} f \mathrm{H}^{-/-}$, and $\mathrm{Klb}^{-/-}$mice have significantly smaller gallbladder volumes (Choi et al. 2006; S Kir, SA Kliewer, and DJ Mangelsdorf, unpubl. observations) and restoring FGF15 to Fgf15 $5^{-/-}$mice restores the gallbladder to its normal volume, implying an essential role for FGF15/19 in gallbladder filling (Choi et al. 2006). Cholecystokinin (CCK), another intestine-derived postprandial hormone, is a wellknown inducer of gallbladder emptying. FGF15/19 administration was shown to oppose the action of CCK directly by relaxing gallbladder smooth muscle and inducing gallbladder filling in CCK-treated mice (Choi et al. 2006). These findings defined the hormonal basis for gallbladder filling and suggested that bile acids traversing the intestine act as a reset switch for postprandial gallbladder emptying, first by repressing CCK secretion in the duodenum, and second by inducing gallbladder filling by activating FGF19 expression in the ileum (Fig. 1).

\section{FGF19 REGULATES HEPATIC PROTEIN AND GLYCOGEN SYNTHESIS}

Several pharmacologic studies in hyperglycemic, obese animal models have shown that FGF19 can improve metabolic rate and lower serum glucose and hepatic triglyceride and cholesterol levels (Tomlinson et al. 
2002; Fu et al. 2004). To further elucidate the physiologic effects of FGF19 on hepatic metabolism, we investigated FGF19-induced signaling in mouse liver (Kir et al. 2011). FGF19 treatment increased phosphorylation of eukaryotic initiation factor 4B (eIF4B) and eIF4E, which are components of the eIF4F complex that mediates binding of mRNA to the ribosome. Phosphorylation of these proteins has been shown to promote initiation of translation (Gingras et al. 1999). FGF19 also increased phosphorylation of ribosomal subunit S6 (rpS6). Phosphorylation of rpS6 enhances global protein synthesis (Fumagalli and Thomas 2000). In addition, as measured by in vivo ${ }^{2} \mathrm{H}_{2} \mathrm{O}$ labeling, FGF19 stimulated total protein synthesis as well as albumin synthesis in mouse liver (Kir et al. 2011). Thus, by inducing phosphorylation of eIF4B, eIF4E and rpS6, FGF19 stimulates hepatic protein synthesis.

Moreover, FGF19 also induced phosphorylation of glycogen synthase kinase $3 \alpha(\mathrm{GSK} 3 \alpha)$ and GSK $3 \beta$, whose functions include phosphorylation and inactivation of glycogen synthase (GS). Phosphorylation blocks GSK $3 \alpha / \beta$ activity. Thus, by inducing phosphorylation of GSK $3 \alpha / \beta$, FGF19 inhibited phosphorylation of GS and induced GS activity, leading to elevated glycogen levels in mouse liver. Coincident with this finding, FGF19 also increased the glycogen synthesis rate in hyperglycemic clamp experiments in rats. $F g f 15^{-/-}$animals also have reduced liver glycogen and are less efficient than wild-type mice in reducing plasma glucose levels after a glucose load. FGF19 administration completely rescued this glucose intolerance phenotype.
Furthermore, FGF19 induced glycogen synthesis in streptozotocin-treated, diabetic mice with reduced liver glycogen content and almost no serum insulin, demonstrating that FGF19-induced glycogen synthesis is independent of insulin (Kir et al. 2011).

The above studies demonstrated that, like insulin, FGF19 promotes protein and glycogen synthesis in liver. However, the mechanism of FGF19 action is different from that of insulin. Unlike insulin, FGF19 fails to activate the PI3K/Akt signaling pathway. Instead, FGF19 acts through the Ras/ERK pathway (Kurosu et al. 2007; Lin et al. 2007; Kir et al. 2011) to mediate both of these insulin-like effects. For the regulation of protein synthesis, insulin is known to induce the PI3K/Akt/mTOR pathway to phosphorylate and activate $\mathrm{p} 70$ ribosomal S6 kinase (p70S6K), which in turn phosphorylates eIF4B and rpS6. mTOR also phosphorylates eIF4E binding protein (4E-BP), which sequesters eIF4E and is blocked by phosphorylation. In contrast, FGF19 induces phosphorylation of eIF4E via the protein kinase Mnk1, which is activated by ERK. Likewise, FGF19-dependent phosphorylation of eIF4B and rpS6 is mediated by $\mathrm{p} 90$ ribosomal S6 kinase (p90RSK), which is also activated by ERK. For the regulation of glycogen synthesis, insulin has been shown to promote GSK $3 \alpha / \beta$ phosphorylation via Akt, whereas FGF19 acts through p90RSK. Thus, both insulin and FGF19 activate the same downstream targets but use different signaling cascades (Fig. 2). The use of different signaling pathways by FGF19 and insulin permits each hormone to have other distinct effects on liver metabolism. For example, insulin, but

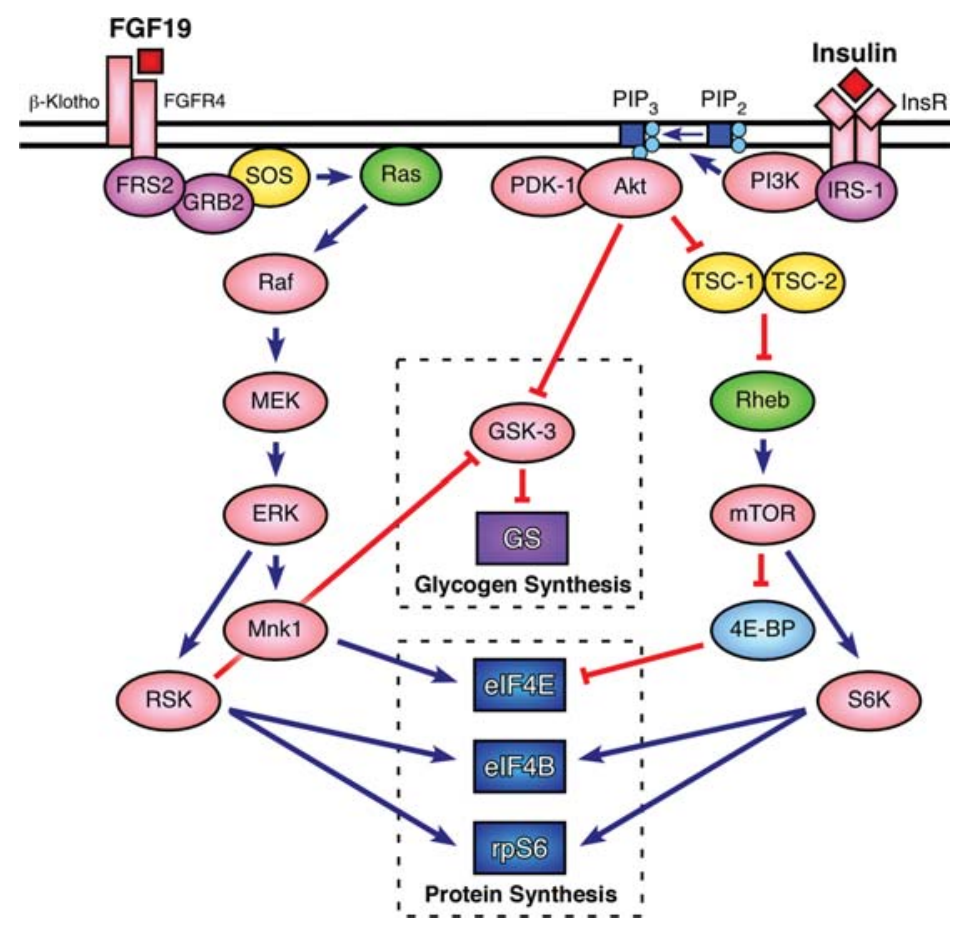

Figure 2. Signaling cascades induced by fibroblast growth factor 19 (FGF19) and insulin. FGF19 activates the Ras/ERK pathway, whereas insulin activates the PI3K/Akt pathway to induce protein and glycogen synthesis. GS, glycogen synthase. 
not FGF19, induces SREBP-1c expression and increases hepatic triglycerides, which is dependent on the PI3K/ Akt signaling (Porstmann et al. 2008; Li et al. 2010).

Another interesting and perhaps physiologically important difference in the action of insulin and FGF19 is the timing of their postprandial release. Maximal serum insulin levels are achieved within $1 \mathrm{~h}$ of a meal. However, serum FGF19 levels peak $\sim 3 \mathrm{~h}$ after a meal (Lundasen et al. 2006), demonstrating that insulin and FGF19 actions are temporally segregated. The late-phase postprandial rise in FGF19 coincides with liver glycogen levels, which peak $\sim 4 \mathrm{~h}$ after a meal in human subjects (Taylor et al. 1996; Krssak et al. 2004). These observations suggest that insulin and FGF19 work in a coordinated temporal fashion to promote hepatic glycogen synthesis. The finding that FGF19 is an important physiological regulator of liver glycogen is supported by studies in liver-specific IRS1/IRS2-deficient mice. These mice lack hepatic insulin signaling yet still retain the ability to store hepatic glycogen in response to feeding, demonstrating that regulators other than insulin are involved (Dong et al. 2006; Kubota et al. 2008).

\section{FGF19 REGULATES HEPATIC GLUCONEOGENESIS}

The liver is the key organ for maintaining blood glucose levels in both fed and fasted states. After a meal, exogenous glucose is used to synthesize glycogen and triglycerides in liver, whereas during fasting gluconeogenesis and glycogenolysis are switched on to produce glucose. These opposing processes are tightly regulated to maintain glucose homeostasis.

As a postprandial hormone, insulin stimulates hepatic glycogen synthesis and lipogenesis, and inhibits gluconeogenesis. As described above, FGF19 also induces glycogen synthesis but, unlike insulin, FGF19 does not increase lipogenesis. Recently Potthoff et al. (2011) described another insulin-like effect of FGF19. In these studies, administration of FGF19 reduced hepatic gluconeogenesis by repressing expression of the transcription factor PGC1 $\alpha$, and the PGC1 $\alpha$ target genes, glucose-6phosphatase (G6pase) and phosphoenolpyruvate carboxykinase $($ Pepck). Coincident with the pharmacological effects of FGF19, Fgfl5 ${ }^{-/-}$and Fgfr $4^{-/-}$mice were shown to have increased Pgcl 1 , G6pase and Pepck mRNA levels. In addition, after a pyruvate/lactate challenge that stimulated gluconeogenesis, $\mathrm{Fgfl5^{-/- }}$ and Fgfr $4^{-/-}$mice had higher blood glucose levels compared with wild-type counterparts, consistent with the finding that gluconeogenesis is elevated in these mice (Potthoff et al. 2011).

Insulin represses gluconeogenic genes by promoting Akt-dependent phosphorylation and subsequent degradation of FOXO1, a transcription factor involved in fastingmediated induction of gluconeogenic gene expression. Because FGF19 does not activate the PI3K/Akt pathway, FOXO1 phosphorylation is not altered by FGF19. Instead, FGF19 regulates another transcription factor involved in gluconeogenic gene expression, cAMP regulatory element binding protein (CREB). FGF19 reduced phosphorylation of CREB and inhibited CREB binding to the Pgc $1 \alpha$ promoter. By down-regulating Pgcl $\alpha$ transcription, FGF19 also represses PGC1 $\alpha$ binding to G6pase and Pepck promoters (Potthoff et al. 2011).

After a meal, endogenous glucose production falls as exogenous glucose appears in the circulation. Gluconeogenesis accounts for approximately half of endogenous glucose production, and the rate of gluconeogenesis stays low up to $\sim 4 \mathrm{~h}$ after a meal (Woerle et al. 2003). Again, when the timing of postprandial insulin and FGF19 levels are considered, the delayed repression of gluconeogenesis implies a coordinated temporal response in which insulin and FGF19 work to repress hepatic gluconeogenesis.

\section{CONCLUSION}

As highlighted in this review, FGF19 functions as a postprandial hormone to govern hepatic protein synthesis, glycogen synthesis and gluconeogenesis, making it remarkably similar to insulin in many ways (Fig. 3). However, unlike insulin, FGF19 does not stimulate lipogenesis. In fact, FGF19 has been shown to reduce hepatic triglycerides and cholesterol through an unknown mechanism (Tomlinson et al. 2002; Fu et al. 2004). Another major difference is the regulation of bile acid homeostasis, which is a hallmark role of FGF19 in liver metabolism. In contrast, insulin is not considered as a primary regulator of bile acid biology (Table 1).

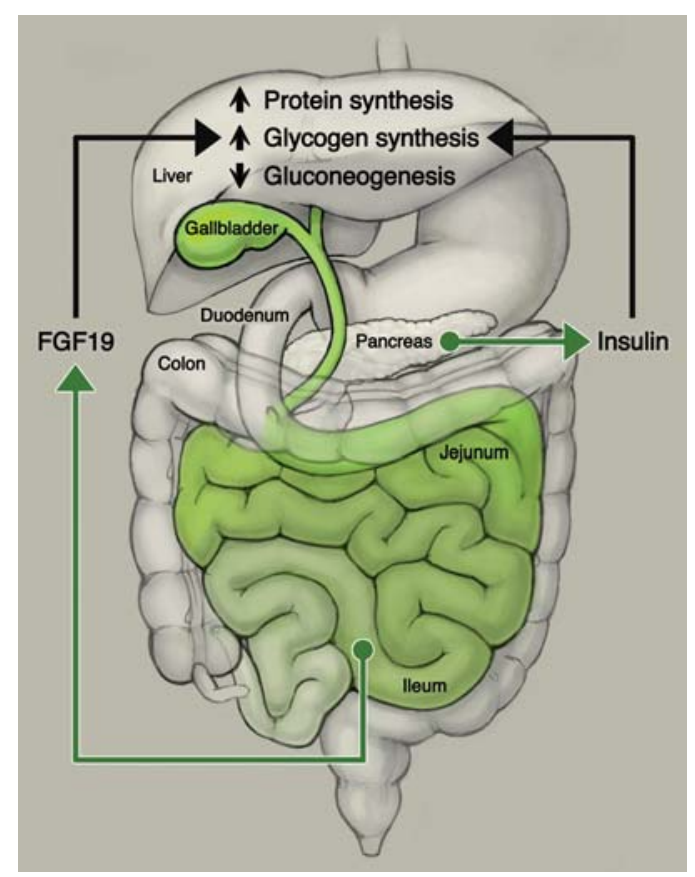

Figure 3. Fibroblast growth factor 19 (FGF19) is an ileumderived postprandial enterokine that regulates hepatic protein and glucose metabolism. Both FGF19 and insulin promote protein and glycogen synthesis and inhibit gluconeogenesis in liver. 
Table 1. Metabolic effects of FGF19 and insulin in liver

\begin{tabular}{lcc}
\hline & FGF19 & Insulin \\
\hline Bile acid synthesis & $\downarrow$ & - \\
Protein synthesis & $\uparrow$ & $\uparrow$ \\
Glycogen synthesis & $\uparrow$ & $\uparrow$ \\
Gluconeogenesis & $\downarrow$ & $\downarrow$ \\
Lipogenesis & - & $\uparrow$ \\
Triglycerides & $\downarrow$ & $\uparrow$ \\
Cholesterol & $\downarrow$ & - \\
\hline
\end{tabular}

These overlapping but distinct functions of FGF19 and insulin raise the intriguing possibility of using FGF19 as a therapeutic agent in the treatment of both type I and type II diabetes. The nonlipogenic, triglyceride/cholesterollowering, and insulin-sensitizing effects of FGF19 make this notion even more appealing. Nevertheless, there are concerns about the potential for using FGF19 as a chronic therapeutic. Transgenic mice that continually overexpress FGF19 eventually form liver tumors (Nicholes et al. 2002) and FGF19 has been implicated as an associated factor with hepatocellular carcinoma (Ho et al. 2009). However, whether exogenous administration of FGF19 can cause similar effects is still not clear. There is also the possibility of separating mitogenic and metabolic effects of FGF19 by generating synthetic FGF19 variants that do not stimulate cell proliferation $(\mathrm{Wu}$ et al. 2010, 2011). A closely related member of the FGF19 subfamily, FGF21, has also been shown to have profound effects on metabolism. FGF21 reduces plasma glucose, triglyceride, and insulin parameters, and improves insulin sensitivity in diabetic animal models. Unlike FGF19, FGF21 does not show significant mitogenic effects and thus may have greater therapeutic promise (Kharitonenkov et al. 2005). Thus, engineering of easily administrable, modified peptide variants of these hormones has the potential to define the future of metabolic syndrome treatment.

\section{ACKNOWLEDGMENTS}

This work was supported by the Robert A. Welch Foundation (grants I-1275 to D.J.M. and I-1558 to S.A.K.) and the Howard Hughes Medical Institute (D.J.M.). This work was presented as a poster at the Cold Spring Harbor Symposium on Metabolism and Disease, 2011.

\section{REFERENCES}

Beenken A, Mohammadi M. 2009. The FGF family: Biology, pathophysiology and therapy. Nat Rev Drug Discov 8: 235-253.

Choi M, Moschetta A, Bookout AL, Peng L, Umetani M, Holmstrom SR, Suino-Powell K, Xu HE, Richardson JA, Gerard $\mathrm{RD}$, et al. 2006. Identification of a hormonal basis for gallbladder filling. Nat Med 12: 1253-1255.

Dong X, Park S, Lin X, Copps K, Yi X, White MF. 2006. Irs1 and Irs2 signaling is essential for hepatic glucose homeostasis and systemic growth. J Clin Invest 116: 101-114.

Fu L, John LM, Adams SH, Yu XX, Tomlinson E, Renz M, Williams PM, Soriano R, Corpuz R, Moffat B, et al. 2004. Fibroblast growth factor 19 increases metabolic rate and reverses dietary and leptin-deficient diabetes. Endocrinology 145: 2594-2603.

Fumagalli S, Thomas G. 2000. In Translational control of gene expression (eds. Sonenberg N, Hershey JWB, Mathews MB), pp. 695-717. Cold Spring Harbor Laboratory Press, Cold Spring Harbor, NY.

Gingras AC, Raught B, Sonenberg N. 1999. eIF4 initiation factors: Effectors of mRNA recruitment to ribosomes and regulators of translation. Annu Rev Biochem 68: 913-963.

Ho HK, Pok S, Streit S, Ruhe JE, Hart S, Lim KS, Loo HL, Aung MO, Lim SG, Ullrich A. 2009. Fibroblast growth factor receptor 4 regulates proliferation, anti-apoptosis and $\alpha$-fetoprotein secretion during hepatocellular carcinoma progression and represents a potential target for therapeutic intervention. $J$ Hepatol 50: 118-127.

Holt JA, Luo G, Billin AN, Bisi J, McNeill YY, Kozarsky KF, Donahee M, Wang DY, Mansfield TA, Kliewer SA, et al. 2003. Definition of a novel growth factor-dependent signal cascade for the suppression of bile acid biosynthesis. Genes Dev 17: 1581-1591.

Inagaki T, Choi M, Moschetta A, Peng L, Cummins CL, McDonald JG, Luo G, Jones SA, Goodwin B, Richardson JA, et al. 2005. Fibroblast growth factor 15 functions as an enterohepatic signal to regulate bile acid homeostasis. Cell Metab 2: 217-225.

Ito S, Fujimori T, Furuya A, Satoh J, Nabeshima Y. 2005. Impaired negative feedback suppression of bile acid synthesis in mice lacking $\beta$ Klotho. J Clin Invest 115: 2202-2208.

Kharitonenkov A, Shiyanova TL, Koester A, Ford AM, Micanovic R, Galbreath EJ, Sandusky GE, Hammond LJ, Moyers JS, Owens RA, et al. 2005. FGF-21 as a novel metabolic regulator. J Clin Invest 115: 1627-1635.

Kim I, Ahn SH, Inagaki T, Choi M, Ito S, Guo GL, Kliewer SA, Gonzalez FJ. 2007. Differential regulation of bile acid homeostasis by the farnesoid $\mathrm{X}$ receptor in liver and intestine. J Lipid Res 48: 2664-2672.

Kir S, Beddow SA, Samuel VT, Miller P, Previs SF, SuinoPowell K, Xu HE, Shulman GI, Kliewer SA, Mangelsdorf DJ. 2011. FGF19 as a postprandial, insulin-independent activator of hepatic protein and glycogen synthesis. Science 331: $1621-1624$.

Krssak M, Brehm A, Bernroider E, Anderwald C, Nowotny P, Dalla Man C, Cobelli C, Cline GW, Shulman GI, Waldhäusl W, Roden M. 2004. Alterations in postprandial hepatic glycogen metabolism in type 2 diabetes. Diabetes 53: 3048-3056.

Kubota N, Kubota T, Itoh S, Kumagai H, Kozono H, Takamoto I, Mineyama T, Ogata H, Tokuyama K, Ohsugi M, et al. 2008. Dynamic functional relay between insulin receptor substrate 1 and 2 in hepatic insulin signaling during fasting and feeding. Cell Metab 8: 49-64.

Kurosu H, Choi M, Ogawa Y, Dickson AS, Goetz R, Eliseenkova AV, Mohammadi M, Rosenblatt KP, Kliewer SA, Kuro-o M. 2007. Tissue-specific expression of $\beta$ Klotho and fibroblast growth factor (FGF) receptor isoforms determines metabolic activity of FGF19 and FGF21. J Biol Chem 282: 26687-26695.

Lenicek M, Duricova D, Komarek V, Gabrysova B, Lukas M, Smerhovsky Z, Vitek L. 2011. Bile acid malabsorption in inflammatory bowel disease: Assessment by serum markers. Inflamm Bowel Dis 17: 1322-1327.

Li S, Brown MS, Goldstein JL. 2010. Bifurcation of insulin signaling pathway in rat liver: $\mathrm{mTORC} 1$ required for stimulation of lipogenesis, but not inhibition of gluconeogenesis. Proc Natl Acad Sci 107: 3441-3446.

Lin BC, Wang M, Blackmore C, Desnoyers LR. 2007. Liverspecific activities of FGF19 require Klotho $\beta$. J Biol Chem 282: $27277-27284$.

Lundasen T, Galman C, Angelin B, Rudling M. 2006. Circulating intestinal fibroblast growth factor 19 has a pronounced diurnal variation and modulates hepatic bile acid synthesis in man. J Intern Med 260: 530-536.

Nicholes K, Guillet S, Tomlinson E, Hillan K, Wright B, Frantz GD, Pham TA, Dillard-Telm L, Tsai SP, Stephan JP, et al. 
KIR ET AL.

2002. A mouse model of hepatocellular carcinoma: Ectopic expression of fibroblast growth factor 19 in skeletal muscle of transgenic mice. Am J Pathol 160: 2295-2307.

Porstmann T, Santos CR, Griffiths B, Cully M, Wu M, Leevers S, Griffiths JR, Chung YL, Schulze A. 2008. SREBP activity is regulated by mTORC1 and contributes to Akt-dependent cell growth. Cell Metab 8: 224-236.

Potthoff MJ, Boney-Montoya J, Choi M, He T, Sunny NE, Satapati S, Suino-Powell K, Xu HE, Gerard RD, Finck BN, et al. 2011. FGF15/19 regulates hepatic glucose metabolism by inhibiting the CREB-PGC-1 $\alpha$ pathway. Cell Metab 13: $729-738$.

Sinal CJ, Tohkin M, Miyata M, Ward JM, Lambert G, Gonzalez FJ. 2000. Targeted disruption of the nuclear receptor FXR/ BAR impairs bile acid and lipid homeostasis. Cell 102: 731-744.

Taylor R, Magnusson I, Rothman DL, Cline GW, Caumo A, Cobelli C, Shulman GI. 1996. Direct assessment of liver glycogen storage by $13 \mathrm{C}$ nuclear magnetic resonance spectroscopy and regulation of glucose homeostasis after a mixed meal in normal subjects. $J$ Clin Invest 97: 126-132.

Tomlinson E, Fu L, John L, Hultgren B, Huang X, Renz M, Stephan JP, Tsai SP, Powell-Braxton L, French D, et al. 2002. Transgenic mice expressing human fibroblast growth factor-19 display increased metabolic rate and decreased adiposity. Endocrinology 143: 1741-1747.

Walters JR, Tasleem AM, Omer OS, Brydon WG, Dew T, le Roux CW. 2009. A new mechanism for bile acid diarrhea: Defective feedback inhibition of bile acid biosynthesis. Clin Gastroenterol Hepatol 7: 1189-1194.

Woerle HJ, Meyer C, Dostou JM, Gosmanov NR, Islam N, Popa E, Wittlin SD, Welle SL, Gerich JE. 2003. Pathways for glucose disposal after meal ingestion in humans. Am J Physiol Endocrinol Metab 284: E716-E725.

Wu X, Ge H, Lemon B, Vonderfecht S, Baribault H, Weiszmann J, Gupte J, Gardner J, Lindberg R, Wang Z, et al. 2010. Separating mitogenic and metabolic activities of fibroblast growth factor 19 (FGF19). Proc Natl Acad Sci 107: $14158-14163$.

Wu AL, Coulter S, Liddle C, Wong A, Eastham-Anderson J, French DM, Peterson AS, Sonoda J. 2011. FGF19 regulates cell proliferation, glucose and bile acid metabolism via FGFR4-dependent and independent pathways. PLoS One 6: e17868.

Yu C, Wang F, Kan M, Jin C, Jones RB, Weinstein M, Deng CX, McKeehan WL. 2000. Elevated cholesterol metabolism and bile acid synthesis in mice lacking membrane tyrosine kinase receptor FGFR4. J Biol Chem 275: 15482-15489. 


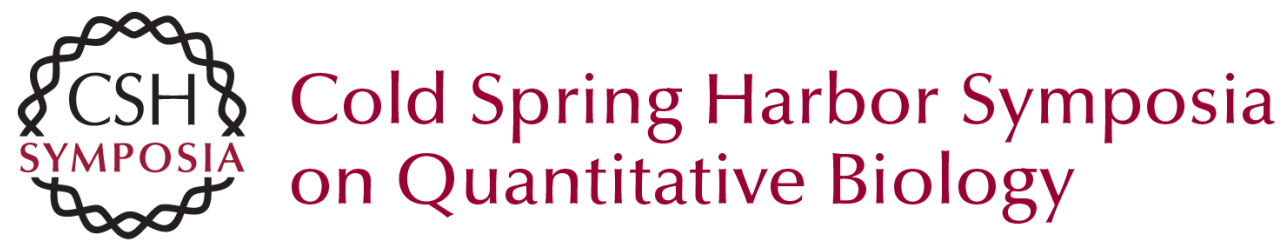

\section{Roles of FGF19 in Liver Metabolism}

S. Kir, S.A. Kliewer and D.J. Mangelsdorf

Cold Spring Harb Symp Quant Biol 2011 76: 139-144 originally published online August 3, 2011 Access the most recent version at doi:10.1101/sqb.2011.76.010710

References This article cites 30 articles, 9 of which can be accessed free at: http://symposium.cshlp.org/content/76/139.full.html\#ref-list-1

\section{License}

Email Alerting Receive free email alerts when new articles cite this article - sign up in Service the box at the top right corner of the article or click here. 